\title{
REMIX DIGITAL E COMPOSIÇÃO VISUAL NO DESIGN GRÁFICO CONTEMPORÂNEO
}

\author{
Ricardo José Barbosa Olimpio \\ Universidade Anhembi Morumbi \\ rickolimpio@live.com \\ Gisela Belluzzo de Campos \\ Universidade Anhembi Morumbi \\ gbcampos@anhembi.br
}

Resumo: Este artigo investiga questões relacionadas aos processos criativos e a resultados gráficos advindos da prática do remix digital em produtos de design. Entende-se por remix digital o uso e o acúmulo de imagens e camadas de diferentes procedências tais como desenhos manuais, objetos sintetizados e fotografias escaneadas, processados graficamente por meio de ferramentas computacionais. $\mathrm{O}$ artigo aborda o processo de criação e produção de peças gráficas criadas pelo designer Rico Lins para a comemoração dos 30 anos do Rock in Rio. Os conceitos empregados para a análise são trabalhados a partir de textos de Lev Manovich, Edmond Couchot, Ellen Lupton e Rick Poynor, entre outros autores. Herdeiro da técnica da colagem, o remix digital propõe uma visualidade construída a partir de elementos díspares cuja lógica difere bastante de produções nas quais reinam a clareza e a objetividade das imagens e visa corporificar o imaginário em uma superfície.

Palavras-chave: Design gráfico contemporâneo, remix, tecnologia digital.

\begin{abstract}
This article investigates issues related to creative processes and graphical results arising from the practice of digital remix in design products. It is understood by digital remix the use and accumulation of images and layers of different sources such as hand drawings, synthesized objects and scanned photographs, processed graphically through computational tools. The article discusses the process of creation and production of graphic pieces created by the designer Rico Lins for the commemoration of 30 years of Rock in Rio. The concepts used for the analysis are worked from texts by Lev Manovich, Edmond Couchot, Ellen Lupton and Rick Poynor, among other authors. Heir to the "collage", the digital remix offers a visuality built from disparate elements whose logic is quite different that productions in which reign the clarity and the objectivity of the images and aims to embody the imagination on a surface.
\end{abstract}

Keywords: Contemporary design graphic, remix, digital technology. 


\section{INTRODUÇÃO}

O design gráfico contemporâneo tem explorado de forma significativa as possibilidades geradas pelos avanços computacionais, incessantes desde o final da década de 1980, na construção de imagens e estilos para compor mensagens visuais (POYNOR, 2010). Busca-se, neste artigo, refletir sobre a aplicação de procedimentos que conduzem tais projetos gráficos, especificamente sobre as "colagens digitais" ou técnicas de remix, com a finalidade de entender como são processadas essas construções e que tipo de resultado apresentam. A prática do remix digital refere-se à fusão de diferentes partes processadas e unidas por meio de máquinas e técnicas digitais. O termo tem larga aplicação no contexto da música e do audiovisual, sobretudo no trabalho do DJ (disc jockey) e do VJ (vídeo jockey). No trabalho do DJ, trechos de composições variadas são unidas em camadas pelo sintetizador que formará um único elemento sonoro, caracterizando uma colagem. No trabalho do VJ, áudio e imagem são trabalhados em conjunto - trechos de vídeo são unidos para "ilustrar" uma música. Estes profissionais são "editores" que constroem colagens de sons e de imagens, criando produtos realizados, em seus primórdios, de modo analógico, com LPS e vídeos tradicionais e atualmente com softwares específicos desenvolvidos para estas finalidades. Entretanto, o remix é usado em outros contextos uma vez que objetos culturais, os mais diversos, na contemporaneidade passam pelo processo de remixagem. No design, as unidades gráficas trabalhadas em bitmaps e vetores nos diversos programas de computação gráfica tais como o Photoshop e o Illustrator, entre outros, sintetizam este aglomerado de elementos e informações visuais e os transformam em uma única imagem gráfica. As ferramentas digitais facilitam estas práticas tornando-as habituais e, em termos de significado, nos dizem que a hibridação ou hibridização é um fenômeno cultural recorrente e presente na contemporaneidade.

Este artigo é parte de uma pesquisa que investiga os procedimentos forjados pelo remix em imagens gráficas de produtos impressos ou virtuais. Para o artigo, foram enfocados os cartazes desenvolvidos pelo designer Rico Lins em homenagem aos 30 anos do Rock in Rio ${ }^{1}$ e, como suporte, são trazidos exemplos de produções que usaram este recurso no eixo diacrônico. A utilização do termo no contexto do design gráfico deve-se à multiplicidade de técnicas que permeiam e compõem produções nesta categoria de design e o mesmo foi apropriado do conceito cunhado por Manovich (2005) que usa a palavra remixabilidade no âmbito das produções criadas no contexto das tecnologias digitais. No domínio do design gráfico, essas imagens são resultantes da fusão ou acúmulo de camadas de diferentes procedências tais como digitalizadas a partir de desenhos manuais ou de fotografias, geradas diretamente de softwares gráficos, entre outros procedimentos. Vários autores têm trabalhado esta ampliação de figuras compositivas no âmbito do gráfico: Lupton (2008), amplia o leque de elementos tradicionalmente trabalhados na linguagem visual tais como ponto, cor, textura, ritmo, entre outros, relacionados às práticas manuais e mecânicas, e acrescenta novos recursos tais como camadas, transparências e modularidades, próprias do universo digital. Poynor (2010) aponta as modificações sofridas pelo design

\footnotetext{
${ }^{1}$ Festival de música com repercussão internacional criado no Brasil, tendo a sua primeira edição em 1985 no Rio de Janeiro, repercutindo posteriormente para outros países como: Portugal, Espanha e Estados Unidos da América.
} 
gráfico com o advento do digital e enfatiza as configurações visualmente densas e complexas formadas pelas apropriações de elementos diversos facilitadas pela máquina. Santaella (2007), denomina "estéticas tecnológicas" produções híbridas resultantes da interatividade entre as distintas máquinas e tecnologias e assinala que as facilidades de produção que essas máquinas proporcionam fazem com que esta "estética" tenha um protagonismo frente às demais formas de construção de imagens. O termo remix digital engloba todas essas ações.

\section{DA COLAGEM AO REMIX}

A colagem explorada desde o início do século XX com as intervenções do cubismo sintético aplicadas por seus precursores Pablo Picasso e Georges Braque, propunha a inserção de objetos do cotidiano na imagem plasmada na superfície plana com o intuito de propor novas percepções da realidade pela arte e, ao mesmo tempo, distanciar-se dos estratagemas ilusionistas forjados pelo uso da perspectiva linear na construção de composições visuais. A partir do cubismo, a colagem ganha espaço como procedimento de criação de imagens e influencia expressões do universo artístico como as realizadas pelos dadaístas e surrealistas e do design gráfico, algumas décadas depois, no contexto do pós-modernismo. Formadas estruturalmente a partir da apropriação de outras preexistentes, essas imagens, por meio do ato de recortar e colar, resultam em novas articulações de significados e mensagens.

O remix digital é uma forma de colagem potencializada. Diferente de sua antecessora processada manual ou mecanicamente, a "colagem digital" processada nas máquinas e softwares, permeia grande parte das composições imagéticas atuais e estas, podem "mascarar" ou potencializar as diferenças entre as diversas junções e recortes de empréstimos das mais distintas procedências.

O histórico da colagem de uma imagem ou documento desaparece completamente no trabalho final, e os designers habitualmente tentam criar transições perfeitas, invisíveis, entre os elementos. Explicar o processo de cortar e colar pode produzir resultados poderosos que indicam o papel do designer na formação do significado (LUPTON, 2008, p. 182).

Da afirmação de Lupton depreende-se que a prática do remix ou "colagem digital" é corriqueira, e como tal, pode obter resultados semânticos bastantes distintos. O "remix" gráfico-digital pode, por exemplo, simular com perfeição uma outra imagem e assim, esconder sua técnica de recortar e colar; ou pode também, de modo inverso, como produto de uma cultura pós-moderna, deixar aparente essa formação por elementos fragmentados em busca de resultados capazes de criar novos significados a partir de imagens previamente formadas. Esta ideia é contrária ao imperativo de originalidade apregoada por algumas instâncias do modernismo e, "fazer o novo" deixa de ser o objetivo, concretizando muitas vezes significados nos quais predominam a ironia, a paródia e o pastiche pela reciclagem de velhas formas (POYNOR, 2010). O "palimpsesto gráfico"2, resultante da sobreposição de imagens é

\footnotetext{
2 Palimpsesto é a denominação dada às superfícies que apresentam sobreposições de mensagens visuais, algumas vezes regidos de certa "abstração" pelo acúmulo de elementos, que conjuntamente podem ser traduzidos por diversos sentidos.
} 
um outro tipo de resultado que desafia a hierarquia da sintaxe modernista e amplia o leque de possibilidades perceptivas e interpretativas em sua leitura.

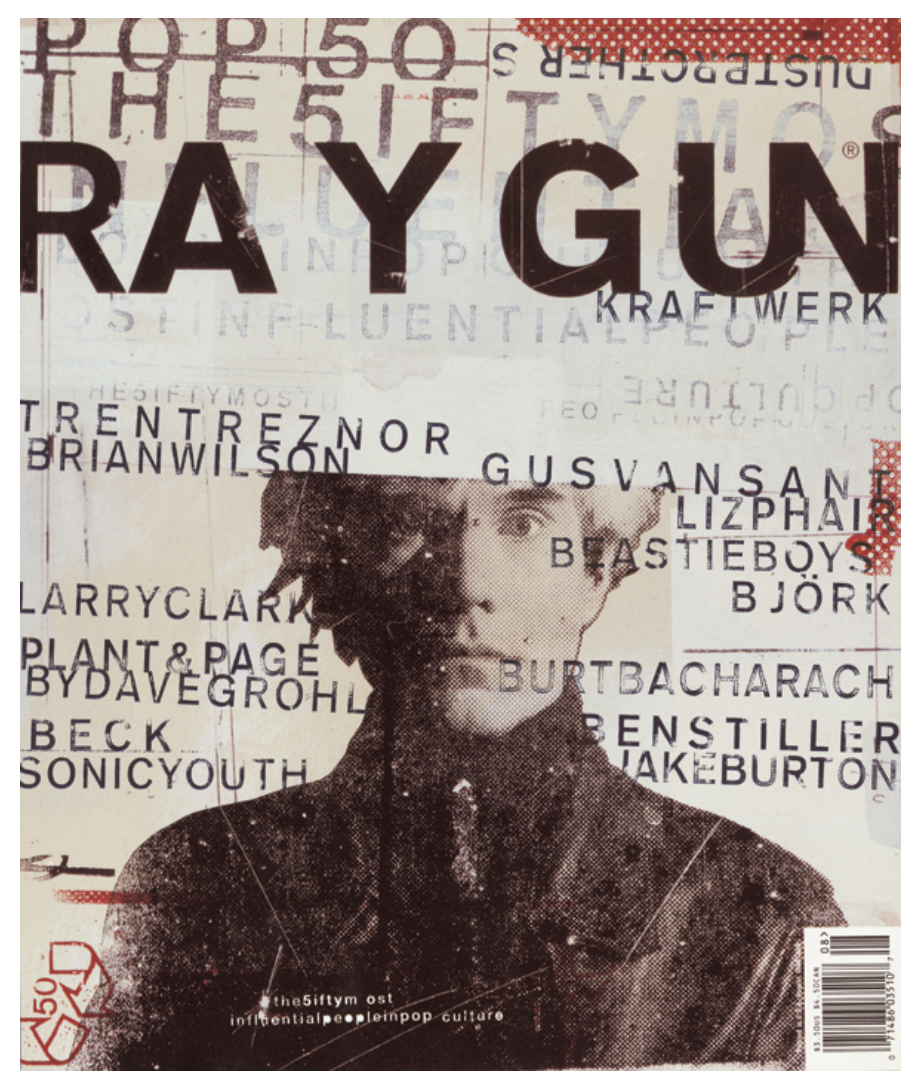

Figura 1 - Capa da revista Ray Gun por David Carson, década de 1990.

Fonte: https://blankdesigner.wordpress.com/category/posts/

No final dos anos 1980 e começo dos anos 1990 tornou-se bastante comum um certo estilo de design gráfico calcado no procedimento da colagem digital no qual fragmentos eram justapostos e sobrepostos com o intuito de explorar as possibilidades oferecidas pelos softwares. Marcaram esta fase, os trabalhos de David Carson (figura 1), Katherine McCoy (figuras 2 e 3) e Neville Brody, entre outros. São produções em que os procedimentos de juntar peças imagéticas distintas, sobrepor camadas e texturas para criar efeitos de profundidade são deixados a mostra. Estes trabalhos são normalmente conhecidos como pós-modernistas, pois diferem da clássica construção e sintaxe modernista, na qual os espaços e funções de cada elemento da linguagem visual são claramente delimitados, visando objetividade e clareza da mensagem. Com o uso do computador pessoal, estes e outros designers exploraram a remixabilidade ou facilidade de unir imagens de distintas procedências e criaram novos formatos e estilos, muitas vezes autorais nos quais é possível perceber expressividade e flexibilidade nas composições. 


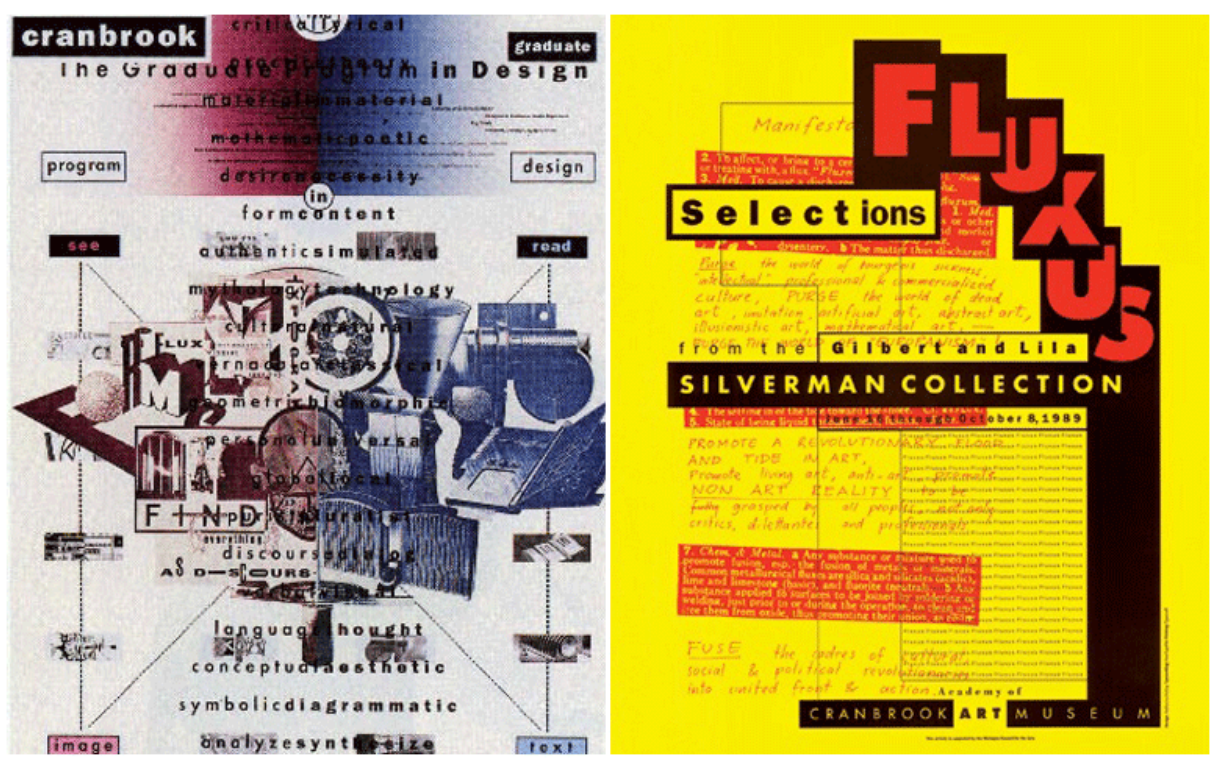

Figura 2 - Katherine McCoy. Divulgação da Cranbrook Academy, 1989.

Figura 3 - Katherine McCoy. Divulgação da exposição “FLUXUS: Selections from the Gilbert and Lila Silverman Collection, 1989.

Fonte: http:// desintegração.tumbir.com/post/40521771140/a-cranbrook-academy-of-art.

\section{COMPONDO O INDEFINIDO}

A forma digital, criada pela simulação, passa por mutações variadas e independe da captação da imagem do mundo real; pode-se primeiramente trabalhar um conceito no próprio imaginário e posteriormente dar corpo a essas imagens, que podem referir-se a segmentos figurativos lúdicos, oníricos ou até mesmo pragmáticos. A manipulação das imagens sintéticas tem o papel protagonizador de gerar os mais variados tipos de mensagens com êxito.

\footnotetext{
Consideremos a natureza da imagem sintética. Ela tem características totalmente específicas em relação às imagens obtidas com os meios audiovisuais tradicionais: de fato, antes de ser reprodução da visão de um objeto concreto, ela deriva de uma matriz numérica e de procedimentos lógico-matemáticos; o seu espaço e o seu tempo são virtuais; os signos que as constituem são os dos objetos manipuláveis (posso mover no espaço um sólido geométrico que criei); ela substitui à análise inicial do objeto a síntese derivada do modelo (BETTETINI, 1996, p. 68-69).
}

Na colagem mediada pela computação gráfica, é notória a construção de figuras combinadas por uma somatória de híbridos que, por meio da remixagem alcançam resultados de destaque. Para o designer, os principais benefícios do advento do computador são: poder trabalhar livremente com infinita margem de segurança, agenciar seu método de produção, ter liberdade e fluidez ao manipular as unidades gráficas sem deixar rastros no desfazer ou refazer ações; ter autonomia na tomada de decisões para possíveis alterações, mesmo quando o resultado da imagem parecer "correto" (POYNOR, 2010). Isso possibilita maior liberdade criativa e maior autonomia na escolha do esquema visual o que contribui também para a realização de trabalhos mais autorais. Um projeto pode começar com uma finalidade definida e, no meio do caminho, encontrar um novo trajeto e testar novas possiblidades, ou até mesmo, encontrar atalhos inesperados rumo ao seu objetivo. 
Opera-se hoje, através do computador, com uma inteligência matemática produtora de imagens "irreais" ou "imateriais". Instância, portanto, de criação de imagens, posta a serviço da imaginação científica, estética ou lúdica (LUZ, 1996. p. 49).

Para que a imagem de um projeto gráfico ganhe corpo, o PC (personal computer) conta com o auxílio de softwares e aparatos eletrônicos adjacentes que, por intermédio da interatividade multidisciplinar em suas funções, proporcionará os resultados visuais esperados. Em conformidade com a suposição de Rogério Luz (1996), ao surgir novas tecnologias, possibilidades de linguagens vão sendo desenvolvidas conforme os níveis de pensamentos direcionados ao que se pretende compor, estimulando novos direcionamentos em repertório e percepção. Como resultado desses esforços, apresentam-se as imagens sintéticas, que em sua gênese possuem características intrínsecas às que que estamos tradicionalmente habituados a captar pela retina, pois antes de reproduzir algo concreto, são derivadas de cálculos matemáticos pré-dispostos a manipulações (BETTETINI, 1996).

Essas imagens remixadas a imagens capturadas de fontes externas e analógicas, possibilitam o surgimento de imagens híbridas que desafiam aspectos estilísticos e padrões visuais consagrados e assimilados; podem incorporar o erro e o acaso e resultar em composições conceitualmente ricas pela junção do "real" e do que aparece como resultado não previsto pelo designer. $O$ trabalho de Rico Lins insere-se neste contexto. Em entrevista concedida por correio eletrônico aos autores deste artigo, o designer afirma considerar o remix digital aplicado ao design contemporâneo "fundamental e bem-vindo, sobretudo num ambiente onde o virtual se confunde tanto com o real e o híbrido digital-analógico se faz tão presente" (LINS, 2016).

O recurso à colagem digital é um método de criação presente em suas produções sempre acompanhada de um rigor conceitual que legitima o procedimento.

A colagem se expandiu muito tecnicamente no ambiente digital, mas nem sempre é acompanhada de um aprofundamento conceitual, sobretudo quando se leva o software muito a sério. Uma das coisas mais interessantes no digital é a possibilidade e o acesso à mistura de diferentes linguagens como o gráfico com a música, o ritmo, o técnico, o erro, o acaso. Além do acesso a referências históricas e culturais que a internet favorece (LINS, 2016).

Os cartazes criados pelo designer em homenagem ao trigésimo ano do "Rock in Rio", expostos na 5a. ArtRio, trazem de forma exemplar o processo de remixabilidade. O procedimento de criação bastante original, teve início com a composição de um conjunto tipográfico baseado em um objeto escolhido como representativo do evento musical. Rico relata de forma simples e concisa sobre a composição da obra:

Em primeiro lugar, optei por fazer um díptico tipográfico onde a palavra ROCK dialogasse de alguma forma inusitada com IN RIO. Ter usado essa fonte experimental, feita a partir de óculos escuros quebrados me pareceu uma boa escolha pois nela se condensam várias associações que se pode fazer tanto com uma palavra, quanto com a outra. O fato de ter trabalhado cromaticamente, como foi uma cor sendo o negativo da outra, completou a ideia" (LINS, Rico. 2016). 


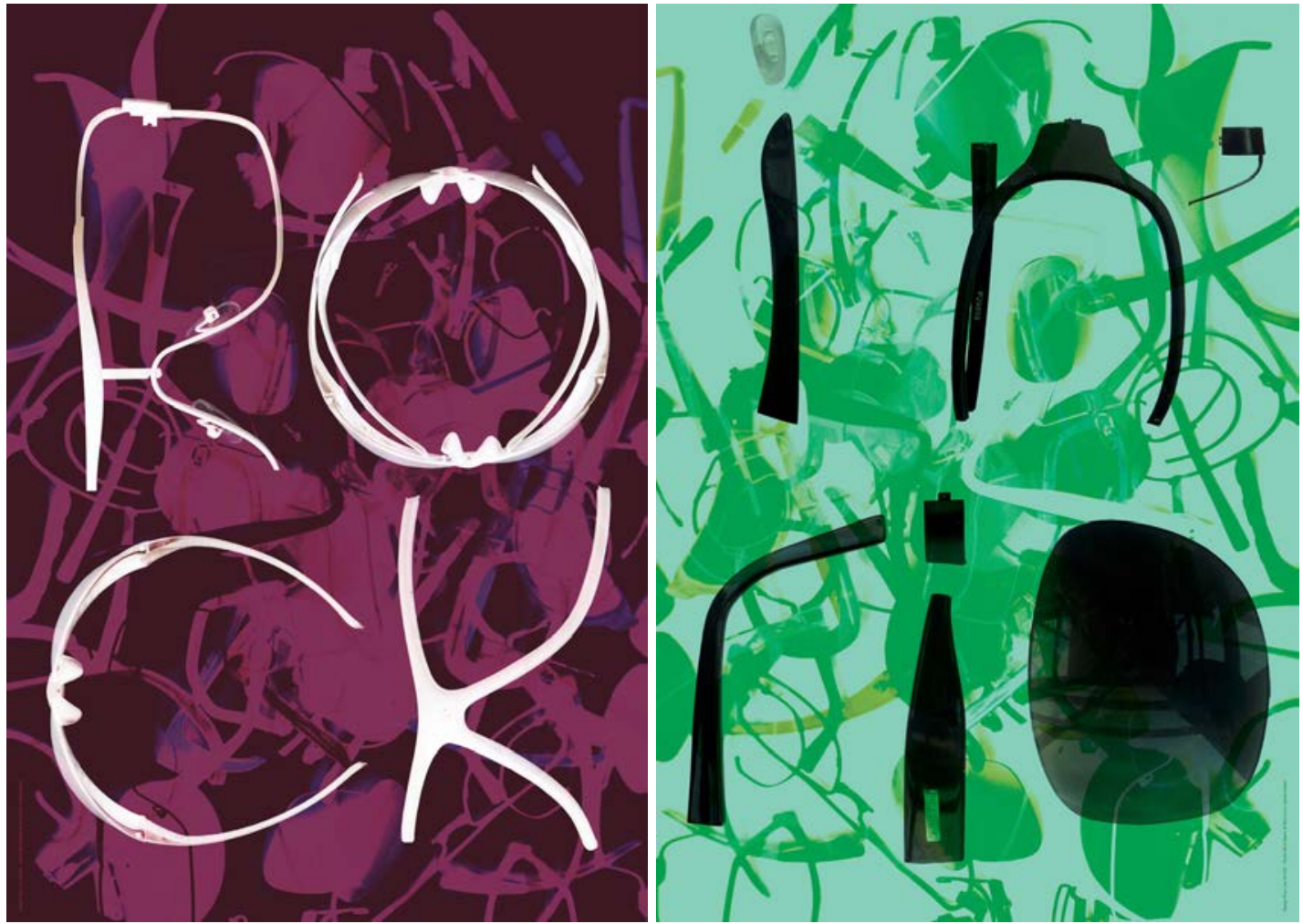

Figura 4 e 5 - Rico Lins. Cartazes em comemoração dos 30 anos de Rock in Rio. Fonte: http://www.ricolins.com/, 2015.

Ambos os cartazes são compostos pela apropriação de imagens que, desconstruídas, possibilitaram a fundamentação de uma configuração visual totalmente original e única referente ao tema em foco. A tipografia de caráter experimental, foi construída por fragmentos elementares de óculos de sol, que após serem desconstruídos, foram fotografados, digitalizados e recombinados entre as suas partes (figura 6), tendo como resultado o corpo tipográfico denominado "Blind Beans" (figuras 7 e 8 ).

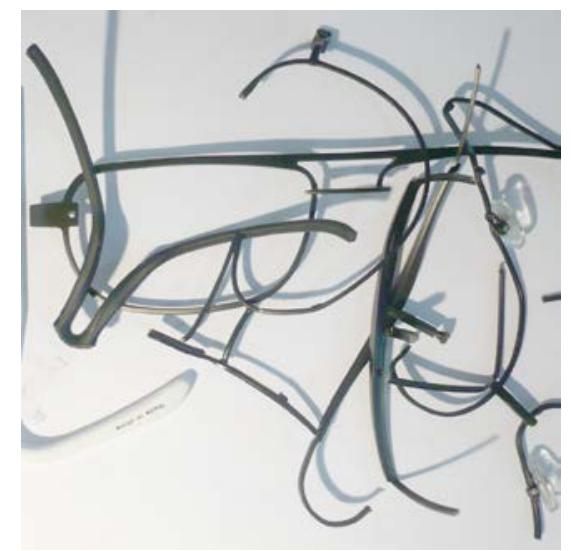

Figura 6 - Fragmentos de óculos utilizados para a construção tipográfica Blind Beans. Fonte: http://www.ricolins.com/, 2015. 


\section{-COEFG \\ HIJKLMN \\ OPORST \\ UVW Y Y $Z$}

Figura 7 - Rico Lins. Tipografia experimental Blind Beans - caixa alta.

Fonte: Rico Lins + Studio. São Paulo, 2015.
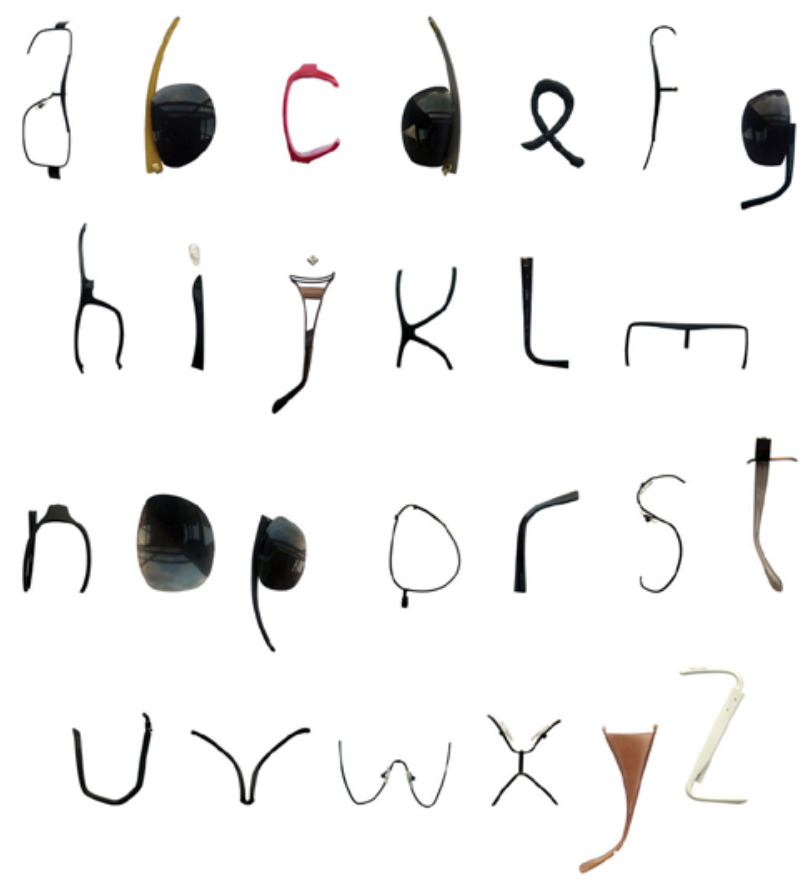

Figura 8 - Rico Lins. Tipografia experimental Blind Beans - caixa baixa.

Fonte: Rico Lins + Studio. São Paulo, 2015.

Os cartazes referentes ao festival "Rock in Rio", dispostos nas figuras 4 e 5 resultam em composições importantes para a construção de uma narrativa dentro de um espaço compartilhado: os elementos são segregados em partes proporcionalmente harmônicas e complementam-se na elaboração da mensagem por meio de camadas tipográficas que, neste caso, promovem uma expressão poética articulada à linguagem proposta (Lupton, 2008). Em suporte às camadas textuais compostas pela tipografia 
experimental Blind Beans, empregam-se os backgrounds formados pela apropriação das mesmas unidades utilizadas na construção dos "tipos" que, sobrepostas e planificadas, resultam em um plano texturizado. "A textura acrescenta detalhes a uma imagem, proporcionando mais qualidade à superfície como um todo e recompensando o olhar daquele que a observa" (LUPTON, 2008, p.53). Em suma, os cartazes estão bem solucionados quanto às disposições gráficas e conceito, exploram as transparências das camadas aplicadas em duas tonalidades com cores secundárias que, combinadas, visam despertar a percepção pelo contraste. "Quanto mais intensa ou saturada for a coloração de um objeto ou acontecimento visual, mais carregado estará de expressão e emoção" (DONDIS, 2007).

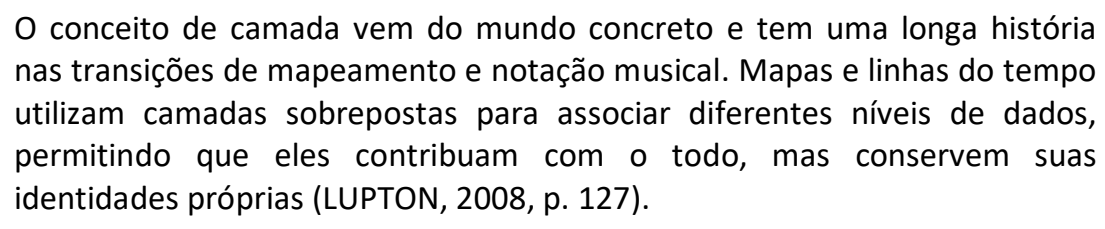

\section{CONCLUSÃO}

Perante as reflexões levantadas neste artigo, podemos considerar a imagem parte relevante em um projeto de design gráfico e, muitas vezes, elemento chave para a construção de um conceito. Graças às possibilidades geradas pelos dispositivos digitais, faz-se possível tanto recriar o mundo real por meio da simulação, como criar novas relações e realidades (COUCHOT, 1996). A técnica do remix, favorece e estimula a liberdade de criar configurações inéditas conforme cada proposta específica as quais não se concentram unicamente na informação, mas também favorecem o aparecimento de soluções imprevisíveis que desafiam o imaginário do designer e do receptor. $O$ design gráfico contemporâneo é beneficiado por essas oportunidades de combinação de imagens advindas das mais diversos origens; pela hibridação e pela remixibilidade propiciadas pelo trabalho digital e, desse modo, é enriquecido em possibilidades semânticas.

\section{REFERÊNCIAS}

\section{Referências de Livro:}

ARNHEIM, Rudolf. Arte e percepção visual: uma psicologia da visão criadora. São Paulo: Pioneira Thomson Learning, 2004.

BETTETINI, Gianfranco. Semiótica, computação gráfica e textualidade. In: PARENTE, André (org.). Imagem e máquina: a era das tecnologias do virtual. Rio de Janeiro: Editora 34, 1996.

COUCHOT, Edmound. Da representação à simulação: evolução das técnicas e das artes da figuração. In: PARENTE, André (org.). Imagem e máquina: a era das tecnologias do virtual. Rio de Janeiro: Editora 34, 1996.

DONDIS, Donis A. Sintaxe da linguagem visual. São Paulo: Martins Fontes, 2007.

LUPTON, Ellen e PHILLIPS, Jennifer Cole. Novos fundamentos do design. São Paulo: Cosac \& Naify, 2008. 
LUZ, Rogério. Novas imagens: Efeitos e modelos. In: PRENTE, André (org.). Imagem e máquina: a era das tecnologias do virtual. Rio de Janeiro: Editora 34, 1996.

POYNOR, Rick. Abaixo as regras: design gráfico e pós-modernismo. Porto Alegre: Bookman, 2010.

SANTAELLA, Lucia. Imagens líquidas na era da mobilidade. São Paulo: Paulus, 2007.

WESCHER, Herta. La historia del collage: del cubismo a la actualidad. Barcelona, 1976.

\section{Entrevista, palestra e discurso:}

LINS, Rico. Entrevista concedida aos autores deste artigo em junho de 2016 por e-mail, pelo designer Rico Lins, proprietário do RICO LINS + STUDIO em São Paulo.

\section{Meio Eletrônico:}

Desintegração. Disponível na internet em http://desinteracao.tumblr.com. Acesso em 04 de junho de 2016.

David Carson Design. Disponível na internet em http://www.davidcarsondesign.com. Acesso em 06 de junho de 2016.

LINS, Rico. Cartazes comemorativos dos 30 anos do Rock in Rio. Rico Lins + Studio: São Paulo, 2015. Disponível na internet em http://www.ricolins.com/portfolio/rock-in-rio/. Acesso em 20 de maio de 2016.

MANOVICH, Lev. (2005). Remixability and modularity. Disponível na internet em http://www. manovich.net. Acesso 05 de junho de 2016.

Rock in Rio Oficial. Disponível na internet em http://rockinrio.com. Acesso em 04 de junho de 2016. 